REVIEW

MECHANISMS IN ENDOCRINOLOGY

\title{
Non-alcoholic fatty liver disease in common endocrine disorders
}

\author{
Jonathan M Hazlehurst and Jeremy W Tomlinson \\ Centre for Diabetes, Endocrinology and Metabolism, School of Clinical and Experimental Medicine, Institute of Biomedical Research, \\ University of Birmingham, Birmingham B15 2YY, UK \\ (Correspondence should be addressed to J W Tomlinson; Email: j.w.tomlinson@bham.ac.uk)
}

\begin{abstract}
Non-alcoholic fatty liver disease (NAFLD) is a spectrum of disease spanning from simple benign steatosis to steatohepatitis with fibrosis and scarring that can eventually lead to cirrhosis. Its prevalence is rising rapidly and is developing into the leading indication for liver transplantation worldwide. Abnormalities in endocrine axes have been associated with NALFD, including hypogonadism, hypothyroidism, GH deficiency and hypercortisolaemia. In some instances, correction of the endocrine defects has been shown to have a beneficial impact. While in patients with type 2 diabetes the association with NAFLD is well established and recognised, there is a more limited appreciation of the condition among common endocrine diseases presenting with hormonal excess or deficiency. In this review, we examine the published data that have suggested a mechanistic link between endocrine abnormalities and NAFLD and summarise the clinical data endorsing these observations.
\end{abstract}

European Journal of Endocrinology 169 R27-R37

\section{Introduction}

Non-alcoholic fatty liver disease (NAFLD) exists as a disease spectrum from the accumulation of lipid within hepatocytes (steatosis) to inflammation of the liver (nonalcoholic steatohepatitis (NASH)) to scarring of the liver (fibrosis) and finally to cirrhosis (1). The prevalence of simple hepatic steatosis in the general population may be as high as $50 \%$, although these studies have varied in terms of the diagnostic criteria and the populations examined (2). The gold standard for diagnosis remains liver biopsy, and $20-50 \%$ of healthy individuals assessed for live partial liver donation have biopsy-proven hepatic steatosis $(3,4)$. In obese cohorts undergoing bariatric surgery, the prevalence of biopsy confirmed that steatosis may be as high as 91 and 37\% for NASH (5).

The impact of simple steatosis on mortality is contentious $(6,7)$ and may reflect differing definitions, observation intervals and the diagnostic methods used to determine the presence of NAFLD. Cardiovascular mortality is increased in NASH cirrhosis even when compared with cirrhosis caused by other aetiologies (8) and is also associated with a 5-year cumulative incidence of hepatocellular carcinoma of $11.3 \%$ (9).

NAFLD is often seen in patients with endocrinopathies $(10,11)$, and it is possible that these observations may shed light onto the aetiological mechanisms underpinning the pathogenesis of NAFLD. Perhaps more importantly, this is a condition that has been overlooked by some endocrinologists and therefore the aim of this review is to not only examine the association and possible causal relationship between endocrinopathies and the development of NAFLD but also raise awareness within the endocrine community.

\section{Pathogenesis of NAFLD}

The pathogenesis of NAFLD has been reviewed extensively elsewhere and is discussed briefly below $(12,13,14)$. Lipid accumulation within the liver represents an equilibrium between synthesis and utilisation. Fatty acids within the liver typically undergo one of the three metabolic pathways: $\beta$-oxidation, storage as triglycerides (TGs) or further processing for secretion as lipoproteins. Lipidomic analysis of liver biopsies from NAFLD and NASH patients has shown that while free fatty acids (FFAs) are unchanged, levels of diacylglycerols and triacylglycerols are increased with elevated saturated fatty acid composition (15). Isotope studies on patients with NAFLD undergoing liver biopsy had dissected the relative contribution of the metabolic pathways that contribute to lipid accumulation within the liver; $59 \%$ were derived from re-esterification of circulating FFAs, 26.1\% from de novo lipogensis and $14.9 \%$ from dietary fatty acids (16).

The increased lipid flux through the liver and dysfunctional lipid metabolism results in intracellular 
stress and apoptosis and consequent liver damage (17). Insulin-resistant adipose tissue with uncontrolled lipolysis resulting in enhanced FFA delivery to the liver has been postulated to be central in driving the pathogenesis of NAFLD. Adipose tissue insulin resistance (IR) has been shown to correlate with severity of liver biopsy findings in NASH (18). The low-grade inflammatory phenotype that is associated with obesity and IR may be important, and adipose tissue tumour necrosis factor $\alpha$ (TNF $\alpha$ ) and circulating interleukin 6 are associated with IR and circulating FFA levels (19) and both are increased in patients with NAFLD and NASH $(20,21)$. In addition, adiponectin, which is produced by mature adipocytes and is known to have an anti-inflammatory action as well as being associated with insulin sensitisation, is decreased in patients with NASH (22).

In summary, the pathogenesis underpinning NAFLD is complex and relies upon crosstalk between the liver and adipose tissues. A three-hit hypothesis has been proposed $(14,23)$; the first hit involves the accumulation of lipid by the mechanisms described above. The second hit is the initiation of an inflammatory response and the triggers to this are still to be clearly defined, but the cell death that is associated with this is the hallmark of progressive disease. Finally, there is emerging evidence to suggest that the third hit is a defective repair and regenerative response (24). It is entirely plausible that endocrine abnormalities with hormonal deficiencies and excess may contribute to any one of these 'hits' and therefore may be implicated in the pathogenesis of NAFLD. In this review, we will examine both the mechanistic and the clinical data that have led to the implication of endocrine axes in the pathogenesis of NALFD.

\section{Hormonal axes and the development of NAFLD Androgens}

There is emerging data implicating androgens in the pathogenesis of NAFLD that is of relevance to hypogonadal men, those on testosterone replacement as well as the hypogonadism associated with obesity. In addition, circulating and tissue-specific androgen excess in the context of polycystic ovary syndrome (PCOS) may be important in its association with NAFLD.

Having entered the cell, androgens bind to the androgen receptor (AR) and translocate to the nucleus to modulate gene transcription. Mice with liver-specific deletion of the AR develop a greater degree of hepatic steatosis in comparison with obese controls (25). Translational studies have endorsed these findings and have demonstrated an association between hepatic steatosis and low serum testosterone levels $(26,27)$. In a retrospective cross-sectional study of 495 men, 251 were identified with NAFLD using abdominal ultrasound scanning and the absence of an alternative aetiology; serum testosterone concentrations were lower in this group ( 1.4 vs $1.7 \mathrm{pmol} / \mathrm{l})$. Serum testosterone levels were subsequently divided into quintiles and using multiple logistic regression to take account of confounding variables including age, smoking, diabetes, exercise, body mass index (BMI), triglycerides (TGs), high-density lipoproteins (HDL), homeostatic model assessment- insulin resistance (HOMA-IR), C-reactive protein (CRP) and visceral adipose tissue, the lowest quintile of testosterone concentrations $(0-1.1 \mathrm{pmol} / \mathrm{l})$ had an odds ratio of 4.52 (2.09-9.80) for the presence of NAFLD (26). In a further retrospective cohort study including 1912 men, hepatic steatosis was also associated with lower serum testosterone levels (14.2 vs $17.2 \mathrm{nmol} / \mathrm{l})$ (27). When patients were divided into quintiles according to serum testosterone and adjusting for the above confounders, low serum testosterone remained associated with hepatic steatosis. Visceral adiposity is a significant risk factor for the development of fibrosis associated with NAFLD (28). A single, 8-year longitudinal study has shown an inverse correlation between serum testosterone and increased BMI and waist circumference (29), suggesting that changes in circulating androgens over time may alter the risk of development of NAFLD.

While there are mechanistic data from preclinical models and observational data linking testosterone levels and NAFLD, there are emerging interventional data. Testosterone replacement in hypogonadal men causes a significant reduction in weight, BMI, waist circumference and circulating TNF $\alpha$ (30). In obese men with obstructive sleep apnoea, testosterone treatment reduced liver fat as measured by computed tomography (CT) without a reduction in BMI or weight (31). Although deranged liver enzymes are poorly predictive of steatohepatitis, testosterone administration has also been shown to decrease alanine transaminase (ALT) and aspartate transaminase (32).

\section{Polycystic ovarian syndrome}

PCOS is a complex condition characterised by IR and androgen excess $(33,34)$. The prevalence of NAFLD within cohorts of obese PCOS patients is elevated and may be as high as 70\% (35). Free androgens, IR and NAFLD prevalence are higher in obese patients with PCOS compared with obese, BMI-matched controls, suggesting that PCOS rather than obesity and its associated features is crucial in the development of NAFLD (35). The relative contribution of IR vs androgen excess has been explored in other studies, but the data remain conflicting. In PCOS patients with and without NAFLD, it is IR rather than androgen excess that correlates most closely with the presence of NAFLD (36). Furthermore, in lean patients with PCOS and IR, there was no increase in NAFLD compared with controls (37). In contrast, in a further study in which patients with PCOS matched for obesity and IR with control subjects, hepatic steatosis was associated with higher 
circulating androgen levels (38). It is therefore likely that a combination of elevated androgens, obesity and IR contribute to the development of NAFLD in PCOS. The difficulty in teasing out the relationship is augmented by our lack of understanding of the pathogenesis of PCOS and it is inconceivable that this is identical in all patients bearing in mind the variety of clinical presentations associated with the diagnosis of PCOS.

Metformin has been widely used in the symptomatic treatment of patients with PCOS in an attempt to restore insulin sensitivity (39). It has also been used to treat patients with NAFLD with and without diabetes (40). Treating patients with PCOS and NAFLD with metformin improves both insulin sensitivity and liver enzymes. These improvements are associated with a reduction in measures of IR and in the free androgen index (41). Importantly, weight loss through lifestyle modification, which often forms the mainstay of current treatment approaches, results in liver biopsy-proven improvements in NASH in patients with PCOS (42).

The contrasting effects of testosterone deficiency in men contributing to the development of NAFLD with the potential contribution of androgen excess in women with PCOS raises the potential for a 'physiological window' for testosterone (43). However, this needs to be further explored in larger populations of both men and women.

\section{Oestrogens}

Preclinical data suggest that oestrogens may protect against the development of NAFLD. Oestradiol $\left(\mathrm{E}_{2}\right)$ treated oophorectomised mice fed a high-fat diet have improved insulin sensitivity, reduced hepatic steatosis and increased export of hepatic TGs in comparison with vehicle-treated animals. In mice lacking the oestrogen receptor, these protective effects were not seen (44). Male aromatase knockout mice that are unable to convert androgens to oestrogens develop hepatic steatosis driven by increased de novo lipogensis and fatty acid uptake. Oestrogen replacement protects against this, suggesting a crucial role for aromatase (45). In addition, antogonising oestrogen action using tamoxifen drives hepatic steatosis (46). Importantly, oestrogen receptor expression and activation vary across the female reproductive cycle and this has been implicated in coordinating hepatic lipid metabolism (47).

These preclinical data are endorsed by clinical observations, suggesting that $\mathrm{E}_{2}$ may protect men from the development of NAFLD. In a large crosssectional study in men, low $\mathrm{E}_{2}$ was associated with the presence of hepatic steatosis (48). Furthermore, tamoxifen when used as an adjuvant chemotherapeutic agent in patients with breast cancer is known to be associated with NAFLD (49).

Postmenopausal women are at an increased risk of developing NAFLD, but whether this relates to the accumulation of metabolic risk factors and the ageing process rather than oestrogen deficiency is less clear
(50). There is emerging evidence to suggest that hormone replacement therapy (HRT) may protect against NAFLD (51), but improvements in cardiovascular risk in postmenopausal patients may be secondary to changes in lipid profile (52). Contrasting with these data, in a double-blind randomised control trial using insulin-euglycaemic clamps, HRT reduced insulin sensitivity in postmenopausal non-diabetic women, with no benefit in body composition (53).

\section{GH and insulin-like growth factor 1}

GH and insulin-like growth factor 1 (IGF1) are important for growth and development but are also of ongoing metabolic significance in adult life. GH is secreted by the anterior pituitary under the control of $\mathrm{GH}-$ releasing hormone from the hypothalamus and stimulates the hepatic production of IGF1. Both GH and IGF1 are believed to be important in the regulation of hepatic lipid metabolism (54).

The exact mechanisms by which GH and IGF1 deficiency contribute to liver steatosis and fibrosis are not fully understood. Animal models of GH deficiency develop hepatic steatosis and fibrosis that are ameliorated by the administration of GH or IGF1 (55). Alterations in reactive oxygen species and improved mitochondrial function have been suggested as underpinning mechanisms.

In a large cross-sectional study including 1667 patients diagnosed with NAFLD and 5479 controls, random $\mathrm{GH}$ levels were lower in the NAFLD group $(0.02$ vs $0.11 \mathrm{ng} / \mathrm{ml})$ (56). $\mathrm{GH}$ levels were negatively correlated with other features of the metabolic syndrome and the NAFLD cohort was significantly older. However, GH levels were negatively associated with NAFLD, independent of age, gender, BMI, waist circumference, mean arterial pressure, ALT, gamma-glutamyl transpeptidase (GGT), lipid profile and fasting plasma glucose. In a smaller study of 160 obese patients, liver biopsy demonstrating NASH with a fibrosis score of $\geq 2$ was associated with a GH level of $<0.45 \mathrm{ng} / \mathrm{ml}$ (57). Conversely, a smaller study of 55 patients with NAFLD found no association between grade of fibrosis and $\mathrm{GH}$ concentrations. Perhaps unsurprisingly, as IGF1 is predominantly produced by the liver, there was a negative correlation between IGF1 and fibrosis stage (58) and low levels of circulating IGF1 in patients with NAFLD has been replicated in other studies (59). Using dynamic tests, peak levels of GH and IGF1 are reduced in patients with NAFLD (60), and in patients with pituitary disease, GH deficiency appears to be associated with increased hepatic lipid content (61).

While the cross-sectional observational data are largely consistent, the interventional data are more controversial. In a series of 69 patients with hypopituitarism in whom GH was not replaced, the prevalence of NAFLD on ultrasound scanning was 77 vs $12 \%$ of controls (11). The introduction of $\mathrm{GH}$ replacement 
reduced liver enzyme concentrations and in the five patients who underwent paired biopsies before and after GH replacement, 6-12 months of treatment improved histological findings (11). A further case report has also identified histological improvement in NAFLD following GH replacement therapy (62). Conversely, in a separate study in patients with GHD, GH replacement decreased subcutaneous and visceral but not hepatic fat (63). The causes of GHD in this study were variable and GH was typically not an isolated deficiency and therefore differences in other hormonal replacement regimes may be important.

To date, there is almost no published cross-sectional or interventional data in patients with acromegaly that have specifically examined the prevalence or progression of NAFLD. However, untreated acromegaly is associated with raised serum TGs (64) and IR and a high visceral adiposity index (65). Perhaps unexpectedly, a single study has shown that co-treatment of acromegaly with a somatostatin analogue and the GH receptor antagonist, pegvisomant, increases intrahepatic lipid (66), but further studies are clearly warranted.

\section{Glucocorticoids}

Glucocorticoids (GCs) are produced by the adrenal gland under the control of pituitary ACTH secretion. In addition, they are metabolised at a pre-receptor level by the isoforms of 11 $\beta$-hydroxysteroid dehydrogenase $(11 \beta$-HSD) and the A-ring reductases $(5 \alpha-$ and $5 \beta$-reductase $(5 \alpha \mathrm{R}, 5 \beta \mathrm{R}))$. $11 \beta$-HSD2 inactivates cortisol to cortisone that is subsequently regenerated by $11 \beta$-HSD1 in key metabolic target tissues including adipose tissue and liver. In contrast, cortisol is cleared and inactivated by both $5 \alpha \mathrm{R}$ and $5 \beta \mathrm{R}$.

The actions of GCs upon lipid metabolism in the liver are complex. While in isolation they decrease lipogenesis, in combination with insulin they act synergistically to increase lipid accumulation (67). They also have profound effects on adipose tissue to drive lipolysis as well as adipocyte differentiation. It is their lipolytic action that may well be responsible for enhanced FFA delivery to the liver that may fuel the NAFLD phenotype. Liver-specific disruption of the GC receptor ameliorates lipid accumulation in rodent models (68). In addition, pre-receptor regulation of GC action can also regulate hepatic phenotype. Genetic knockdown of 11ß-HSD1 (69) as well as pharmacological inhibition (70) decreases hepatic steatosis. Interestingly, this may not reflect changes in hepatic GC availability as liver-specific $11 \beta$-HSD1 deletion does not impact significantly on metabolic phenotype and this may point to a more crucial role of GC metabolism within adipose tissue (71). The role of the A-ring reductases has been less well explored, although there is some evidence to suggest that deletion of $5 \alpha \mathrm{R}$ type 1 increases the risk of development of hepatic steatosis (72).
Patients with Cushing's syndrome do develop NAFLD, although this has not been explored in large series. The prevalence of hepatic steatosis measured by liver/spleen attenuation on CT scanning was $20 \%$ in a cohort of 50 patients with Cushing's syndrome (73). Importantly, patients with NAFLD do not have 'mild Cushing's syndrome', although abnormalities of the hypothalamic-pituitary-adrenal (HPA) axis have been described including increase in urinary free cortisol concentrations and a reduction in dexamethasone suppression of plasma cortisol $(74,75)$. Work from our own group has shown that GC metabolism differs between patients with simple steatosis and NASH. In patients with uncomplicated steatosis, $5 \alpha \mathrm{R}$ activity is increased and 11 $\beta$-HSD1 decreased while in those with NASH, the activity of $11 \beta$-HSD1 was increased. This suggests that in simple steatosis, the increased clearance of cortisol may represent a protective response to try to limit lipid accumulation, while in NASH, the opposite effect might be aimed at limiting hepatic inflammation (76). The increase in urinary $5 \alpha$-reduced GC metabolites has been shown in a further study in patients with NAFLD and NASH; however, hepatic expression of $11 \beta$-HSD1 mRNA was similar in patients and those with normal liver on biopsy (77). An additional study has also demonstrated increased $5 \beta R$ activity with increasing hepatic fat (78). Although selective 11ß-HSD1 inhibitors have not been studied in the context of hepatic steatosis, in patients with diabetes, they caused modest improvement in glycaemic control and weight loss and improved lipid profiles $(79,80)$.

\section{Thyroid}

The thyroid hormones, triiodothyronine and thyroxine, are secreted by the follicular cells of the thyroid gland under the control of TSH from the anterior pituitary, which is itself regulated by TRH from the hypothalamus. Thyroid receptor $\alpha$ (THR $\alpha$ ) is ubiquitously expressed; THR $\beta$ is more restricted; however, it is expressed in the liver (81). Thyroid hormones are key regulators of metabolic phenotype, but the demonstration of a clear causal mechanism between thyroid dysfunction and NAFLD has not been established.

Hypothyroidism decreases liver uptake of FFA derived from TGs (82) and is associated with a reduction in adipose tissue lipolysis (83). In addition, TR $\alpha$ knockout mice are protected from hepatic steatosis and peripheral IR (84). Recent work has shown the importance of thyroid hormones for the intrahepatic metabolism of lipids including fatty acid $\beta$-oxidation and delivery of fatty acids to mitochondria (85). Conversely, hyperthyroidism promotes adipose tissue lipolysis (86) and hepatic lipogensis (87).

Overt hypothyroidism has been associated with the development of NAFLD (88). The prevalence of NAFLD, as diagnosed by ultrasound and the exclusion of other causes of hepatic steatosis, in patients with treated 
hypothyroidism was $30.2 \%$ compared with $19.5 \%$ in the control population (10). When adjusted for key determinants of NAFLD risk including age, gender, BMI, hypertension and diabetes, treated hypothyroidism remained predictive (odds ratio 1.38 (1.17-1.62)). The data with respect to subclinical hypothyroidism are more variable with some studies identifying it as an independent risk factor for the presence of hepatic steatosis after correcting for confounding variables (89). However, other studies have failed to confirm this (88).

The reciprocal relationship also appears to hold true. The prevalence of hypothyroidism among a cohort of 246 patients with biopsy-proven NAFLD was 21 vs $9.5 \%$ in 430 age-, gender-, race- and BMI-matched controls (90). In addition, the prevalence of hypothyroidism in patients with NASH is higher than those with more benign disease $(90,91)$. There are currently no published studies that have examined NAFLD in the context of hyperthyroidism.

Pharmacological correction of hypothyroidism is metabolically beneficial, and in a single case report, correction of profound hypothyroidism improved lipid profile and hepatic steatosis, as measured by magnetic resonance spectroscopy (MRS) (92). Administration of thyroid hormones to euthyroid patients is detrimental; however, targeted manipulation of thyroid hormone action could have potential benefits. Endorsing this concept, a hepatic selective TR $\beta$ agonist reduces hepatic steatosis and circulating FFA and TG levels (93), although at present there are no published clinical data.

\section{Glucagon-like peptide-1}

Glucagon-like peptide-1 (GLP1) is principally secreted from the L-cells of the small intestine as a cleavage product of proglucagon. It is crucially important in the incretin effect whereby the insulin secretory response is greater following oral rather than parenteral glucose loading. GLP1 has many beneficial metabolic effects including enhanced glucose-dependent insulin secretion, decreased $\beta$-cell apoptosis, delayed gastric emptying and decreased appetite (94).

The administration of GLP agonists reduces hepatic steatosis and decreases serum glucose, IR and markers of oxidative stress in rodent models $(95,96)$, decreasing the expression of lipogenic genes including SREBP-1c and SCD1 and increasing those involved in $\beta$-oxidation including PPAR $\alpha(95,97)$.

There are only very limited clinical data available examining the effect of GLP1 agonists on NAFLD. As part of studies powered to detect changes in glycaemic control in patients with type 2 diabetes and NAFLD, they caused a reduction in intrahepatic lipid as measured by MRS in addition to reductions in body weight and improved glycaemic control (98). In a separate analysis of type 2 diabetic patients treated with Liraglutide, there was a dose-dependent but non-significant improvement in hepatic steatosis, measured by liver-spleen attenuation ration as well as improvements in abnormal liver function tests (99). In an open-label study, a small cohort of patients with biopsy-proven NAFLD and diabetes were treated with exanatide, 3/8 had a histological improvement after 28 weeks of treatment (100).

\section{Prolactin}

Prolactin is released from the pituitary under the negative feedback of dopamine. Prolactin is also secreted from adipose tissue where regulatory effects upon insulin signalling and adipogenesis have been demonstrated (101). In diet-induced obesity and genetic models of obesity, administration of the dopamine agonist bromocriptine improves hepatic steatosis and markers of mitochondrial oxidative stress; however, prolactin levels were not measured in this study (102).

Despite the evidence to suggest that dopamine agonist treatment may have a beneficial effect on metabolic phenotype causing modest improvement in lipid profiles and in some studies (but not all) body weight and insulin sensitivity, the impact on the incidence and progression of NAFLD has not been examined (103, 104, 105).

\section{Vitamin D}

There is an increasing body of evidence supporting a role for vitamin $\mathrm{D}$ in the control of metabolic phenotype. In rats fed a western diet, vitamin $\mathrm{D}$ depletion exacerbated histological features of NASH as well as increasing markers of oxidative stress and IR (106). Vitamin D depletion is also associated with increased inflammation (107) and phototherapy to restore vitamin D levels reduced hepatic TG accumulation and improved markers of inflammation and fibrosis (107).

In a study of 6567 men who underwent abdominal US and measurement of vitamin D levels, there was a significant association between NAFLD and low vitamin D (108). The lowest tertiles of vitamin D were associated with NAFLD even after adjustment for the presence of other features of the metabolic syndrome. Similar observations have been made in smaller studies; however, in addition, there is some evidence to suggest that vitamin D levels correlate with the stage of fibrosis on liver biopsy (109). Therapeutic interventional trials have not been published.

\section{Insulin}

The association between NAFLD and type 2 diabetes is well established and has been reviewed extensively elsewhere $(110,111)$. Diabetes is an independent risk factor for NAFLD, and in a large cohort of $\sim 170000$ patients with diabetes, the incidence of NAFLD was $18.13 / 10000$ person years compared with 9.55 in $\sim 650000$ control subjects (112). The converse 
relationship is also true. In a 4-year longitudinal study, the proportion of incident diabetes in those with steatosis and an abnormal ALT was $11.8 \%$ compared with $3.5 \%$ in the control group (113). Furthermore, glycaemic control is worse in patients with type 2 diabetes and coexistent NAFLD (114), and there is an increased rate of complications including coronary and cerebrovascular events (114), diabetic nephropathy (115) and death (116). In patients with type 1 diabetes, NAFLD is associated with higher rates of diabetic nephropathy and cardiovascular disease $(117,118)$. The prevalence of ultrasound-diagnosed NAFLD in type 1 diabetes is $\sim 50 \%(117,119)$.

Some of the therapeutic options licensed for the treatment of diabetes have shown some benefit in NAFLD in those patients with diabetes. The data for the use of metformin in NAFLD in non-diabetic individuals are conflicting and it is not currently recommended for the treatment of NAFLD in those patients (120). There is some data showing an improvement in liver biopsy findings following thiazolidinedione treatment in non-diabetic patients with NASH. Despite this, there are limited long-term data regarding the safety of the use of thiazolidinediones in diabetic patients with NASH (120).

In physiological conditions, insulin suppresses lipolysis and glucose production and promotes lipogenesis as well as glucose uptake, utilisation and storage (121). In the hyperinsulinaemic, insulin-resistant state, as seen in NAFLD, this tight homeostatic control of lipid and carbohydrate is partially lost. IR is associated with uncontrolled adipose tissue lipolysis as well as increased hepatic expression of fatty acid transporter proteins required for fatty acid uptake into the liver (122). Furthermore, obesity and IR are associated with increased re-esterification of fatty acids (123). Consequently, IR results in increased lipid flux into the liver and results in increased cases of hepatic steatosis (112). In addition to the re-esterification of fatty acids, $\sim 25 \%$ of the lipid content within the liver of patients with NAFLD is derived from de novo lipogenesis (16). Although insulin promotes lipogenesis, it is clear that systemic IR is also associated with increased hepatic lipogenesis (124). This idea of 'selective' IR whereby insulin fails to suppress hepatic gluconeogenesis while promoting hepatic lipogenesis has been discussed previously but the mechanisms underpinning this are not yet fully elucidated (125). In addition, IR has also been implicated in driving increased $\beta$-oxidation and oxidative stress, which is central to the development of NASH (126).

Hyperinsulinaemia and IR are widely accepted as central to the pathogenesis of NAFLD in the context of type 2 diabetes. There are currently few data examining the relationship between type 1 diabetes mellitus and NAFLD (127). Decreased insulin concentrations in the portal circulation may be important; however, the emerging evidence to suggest a component of IR in patients with type 1 diabetes (128) may implicate similar mechanisms to those observed in type 2 diabetes.

\section{Conclusion}

The rising prevalence of NAFLD is undoubtedly fuelled by the epidemic of obesity, type 2 diabetes and IR. However, it is clear that many common endocrine diseases are associated with the development and progression of NAFLD. It is important that the clinical endocrinologist recognises the presence of the condition and its potentially devastating consequences, albeit over a prolonged period of time. It is not only the realisation that NAFLD is associated with common endocrine diseases that is important but also the realisation that inappropriate over or under replacement of many hormonal therapies has the potential to exacerbate the condition. Understanding the hormonal regulation of NAFLD may well lead to advances in its treatment, and hormonal interventions may offer a therapeutic advance, and in the future, therapies targeted to the liver, or perhaps adipose tissue, may offer to avoid the potential for the adverse systemic effects.

\section{Declaration of interest}

The authors declare that there is no conflict of interest that could be perceived as prejudicing the impartiality of the review reported.

\section{Funding}

This work has been supported by the Medical Research Council (senior clinical fellowship ref. G0802765, J W Tomlinson).

\section{References}

1 Levene AP \& Goldin RD. The epidemiology, pathogenesis and histopathology of fatty liver disease. Histopathology 201261 141-152. (doi:10.1111/j.1365-2559.2011.04145.x)

2 Vernon G, Baranova A \& Younossi ZM. Systematic review: the epidemiology and natural history of non-alcoholic fatty liver disease and non-alcoholic steatohepatitis in adults. Alimentary Pharmacology \& Therapeutics 201134 274-285. (doi:10.1111/ j.1365-2036.2011.04724.x)

3 Lee JY, Kim KM, Lee SG, Yu E, Lim YS, Lee HC, Chung YH, Lee YS \& Suh DJ. Prevalence and risk factors of non-alcoholic fatty liver disease in potential living liver donors in Korea: a review of 589 consecutive liver biopsies in a single center. Journal of Hepatology 200747 239-244. (doi:10.1016/j.jhep.2007.02.007)

4 Marcos A, Fisher RA, Ham JM, Olzinski AT, Shiffman ML, Sanyal AJ, Luketic VA, Sterling RK, Olbrisch ME \& Posner MP. Selection and outcome of living donors for adult to adult right lobe transplantation. Transplantation $200069 \quad 2410-2415$. (doi:10.1097/00007890-200006150-00034)

5 Machado M, Marques-Vidal P \& Cortez-Pinto H. Hepatic histology in obese patients undergoing bariatric surgery. Journal of Hepatology 200645 600-606. (doi:10.1016/j.jhep. 2006.06.013)

6 Ong JP, Pitts A \& Younossi ZM. Increased overall mortality and liver-related mortality in non-alcoholic fatty liver disease. Journal of Hepatology 200849 608-612. (doi:10.1016/j.jhep. 2008.06.018) 
7 Lazo M, Hernaez R, Bonekamp S, Kamel IR, Brancati FL, Guallar E \& Clark JM. Non-alcoholic fatty liver disease and mortality among US adults: prospective cohort study. BMJ 2011 343 d6891. (doi:10.1136/bmj.d6891)

8 Sanyal AJ, Banas C, Sargeant C, Luketic VA, Sterling RK, Stravitz RT, Shiffman ML, Heuman D, Coterrell A, Fisher RA et al. Similarities and differences in outcomes of cirrhosis due to nonalcoholic steatohepatitis and hepatitis C. Hepatology 200643 682-689. (doi:10.1002/hep.21103)

9 Yatsuji S, Hashimoto E, Tobari M, Taniai M, Tokushige K \& Shiratori K. Clinical features and outcomes of cirrhosis due to non-alcoholic steatohepatitis compared with cirrhosis caused by chronic hepatitis C. Journal of Gastroenterology and Hepatology 200924 248-254. (doi:10.1111/j.1440-1746.2008.05640.x)

10 Chung GE, Kim D, Kim W, Yim JY, Park MJ, Kim YJ, Yoon JH \& Lee HS. Non-alcoholic fatty liver disease across the spectrum of hypothyroidism. Journal of Hepatology $2012 \quad \mathbf{5 7} \quad$ 150-156. (doi:10.1016/j.jhep.2012.02.027)

11 Nishizawa H, Iguchi G, Murawaki A, Fukuoka H, Hayashi Y, Kaji H, Yamamoto M, Suda K, Takahashi M, Seo Y et al. Nonalcoholic fatty liver disease in adult hypopituitary patients with GH deficiency and the impact of GH replacement therapy. European Journal of Endocrinology 2012167 67-74. (doi:10.1530/ EJE-12-0252)

12 Cusi K. Role of obesity and lipotoxicity in the development of nonalcoholic steatohepatitis: pathophysiology and clinical implications. Gastroenterology 2012142 711-725.e6. (doi:10.1053/ j.gastro.2012.02.003)

13 Gentile CL, Frye MA \& Pagliassotti MJ. Fatty acids and the endoplasmic reticulum in nonalcoholic fatty liver disease. Biofactors 201137 8-16. (doi:10.1002/biof.135)

14 Dowman JK, Tomlinson JW \& Newsome PN. Pathogenesis of non-alcoholic fatty liver disease. QJM $2010 \quad 103$ 71-83. (doi:10.1093/qjmed/hcp158)

15 Puri P, Baillie RA, Wiest MM, Mirshahi F, Choudhury J, Cheung O, Sargeant C, Contos MJ \& Sanyal AJ. A lipidomic analysis of nonalcoholic fatty liver disease. Hepatology $2007 \mathbf{4 6}$ 1081-1090. (doi:10.1002/hep.21763)

16 Donnelly KL, Smith CI, Schwarzenberg SJ, Jessurun J, Boldt MD \& Parks EJ. Sources of fatty acids stored in liver and secreted via lipoproteins in patients with nonalcoholic fatty liver disease. Journal of Clinical Investigation 2005115 1343-1351. (doi:10. 1172/JCI200523621)

17 Ibrahim SH, Kohli R \& Gores GJ. Mechanisms of lipotoxicity in NAFLD and clinical implications. Journal of Pediatric Gastroenterology and Nutrition 201153 131-140. (doi:10.1097/MPG. Ob013e31820e82a1)

18 Musso G, Cassader M, De Michieli F, Rosina F, Orlandi F \& Gambino R. Nonalcoholic steatohepatitis versus steatosis: adipose tissue insulin resistance and dysfunctional response to fat ingestion predict liver injury and altered glucose and lipoprotein metabolism. Hepatology 201256 933-942. (doi:10.1002/hep. 25739)

19 Kern PA, Ranganathan S, Li C, Wood L \& Ranganathan G. Adipose tissue tumor necrosis factor and interleukin-6 expression in human obesity and insulin resistance. American Journal of Physiology. Endocrinology and Metabolism 2001280 E745-E751.

20 Grigorescu M, Crisan D, Radu C, Grigorescu MD, Sparchez Z \& Serban A. A novel pahtophysiological-based panel of biomarkers for the diagnosis of nonalcoholic steatohepatitis. Journal of Physiology and Pharmacology 201263 347-353.

21 Crespo J, Cayon A, Fernandez-Gil P, Hernandez-Guerra M, Mayorga M, Dominguez-Diez A, Fernandez-Escalante JC \& Pons-Romero F. Gene expression of tumor necrosis factor $\alpha$ and TNF-receptors, p55 and p75, in nonalcoholic steatohepatitis patients. Hepatology 200134 1158-1163. (doi:10.1053/jhep. 2001.29628)
22 Polyzos SA, Toulis KA, Goulis DG, Zavos C \& Kountouras J. Serum total adiponectin in nonalcoholic fatty liver disease: a systematic review and meta-analysis. Metabolism 201160 313-326. (doi:10.1016/j.metabol.2010.09.003)

23 Day CP \& James OF. Steatohepatitis: a tale of two "hits"? Gastroenterology $1998 \mathbf{1 1 4}$ 842-845. (doi:10.1016/S00165085(98)70599-2)

24 Jou J, Choi SS \& Diehl AM. Mechanisms of disease progression in nonalcoholic fatty liver disease. Seminars in Liver Disease $2008 \mathbf{2 8}$ 370-379. (doi:10.1055/s-0028-1091981)

25 Lin HY, Yu IC, Wang RS, Chen YT, Liu NC, Altuwaijri S, Hsu CL, Ma WL, Jokinen J, Sparks JD et al. Increased hepatic steatosis and insulin resistance in mice lacking hepatic androgen receptor. Hepatology 200847 1924-1935. (doi:10.1002/hep.22252)

26 Kim S, Kwon H, Park JH, Cho B, Kim D, Oh SW, Lee CM \& Choi HC. A low level of serum total testosterone is independently associated with nonalcoholic fatty liver disease. BMC Gastroenterology 201212 69. (doi:10.1186/1471-230X-12-69)

27 Volzke H, Aumann N, Krebs A, Nauck M, Steveling A, Lerch MM, Rosskopf D \& Wallaschofski H. Hepatic steatosis is associated with low serum testosterone and high serum DHEAS levels in men. International Journal of Andrology 201033 45-53. (doi:10.1111/ j.1365-2605.2009.00953.x)

28 Petta S, Amato MC, Di Marco V, Camma C, Pizzolanti G, Barcellona MR, Cabibi D, Galluzzo A, Sinagra D, Giordano C et al. Visceral adiposity index is associated with significant fibrosis in patients with non-alcoholic fatty liver disease. Alimentary Pharmacology \& Therapeutics 201235 238-247. (doi:10.1111/ j.1365-2036.2011.04929.x)

29 Gapstur SM, Gann PH, Kopp P, Colangelo L, Longcope C \& Liu K. Serum androgen concentrations in young men: a longitudinal analysis of associations with age, obesity, and race. The CARDIA male hormone study. Cancer Epidemiology, Biomarkers $\mathcal{E}$ Prevention 200211 (10 Pt 1) 1041-1047.

30 Kalinchenko SY, Tishova YA, Mskhalaya GJ, Gooren LJ, Giltay EJ \& Saad F. Effects of testosterone supplementation on markers of the metabolic syndrome and inflammation in hypogonadal men with the metabolic syndrome: the double-blinded placebocontrolled Moscow study. Clinical Endocrinology $2010 \quad 73$ 602-612. (doi:10.1111/j.1365-2265.2010.03845.x)

31 Hoyos CM, Yee BJ, Phillips CL, Machan EA, Grunstein RR \& Liu PY. Body compositional and cardiometabolic effects of testosterone therapy in obese men with severe obstructive sleep apnoea: a randomised placebo-controlled trial. European Journal of Endocrinology 2012167 531-541. (doi:10.1530/ EJE-12-0525)

32 Haider A, Gooren LJ, Padungtod P \& Saad F. Improvement of the metabolic syndrome and of non-alcoholic liver steatosis upon treatment of hypogonadal elderly men with parenteral testosterone undecanoate. Experimental and Clinical Endocrinology $\mathcal{E}$ Diabetes 2010118 167-171. (doi:10.1055/s-0029-1202774)

33 Rotterdam ESHRE/ASRM-Sponsored PCOS consensus workshop group. Revised 2003 consensus on diagnostic criteria and longterm health risks related to polycystic ovary syndrome (PCOS). Human Reproduction 200419 41-47. (doi:10.1093/humrep/ deh098)

34 Azziz R, Carmina E, Dewailly D, Diamanti-Kandarakis E, EscobarMorreale HF, Futterweit W, Janssen OE, Legro RS, Norman RJ, Taylor $\mathrm{AE}$ et al. Positions statement: criteria for defining polycystic ovary syndrome as a predominantly hyperandrogenic syndrome: an Androgen Excess Society guideline. Journal of Clinical Endocrinology and Metabolism $2006 \quad 91$ 4237-4245. (doi:10.1210/jc.2006-0178)

35 Zueff LF, Martins WP, Vieira CS \& Ferriani RA. Ultrasonographic and laboratory markers of metabolic and cardiovascular disease risk in obese women with polycystic ovary syndrome. Ultrasound in Obstetrics \& Gynecology 201239 341-347. (doi:10.1002/uog. 10084)

36 Kauffman RP, Baker TE, Baker V, Kauffman MM \& Castracane VD. Endocrine factors associated with non-alcoholic fatty liver 
disease in women with polycystic ovary syndrome: do androgens play a role? Gynecological Endocrinology $201026 \quad 39-46$. (doi:10.3109/09513590903184084)

37 Markou A, Androulakis II, Mourmouris C, Tsikkini A, Samara C, Sougioultzis S, Piaditis G \& Kaltsas G. Hepatic steatosis in young lean insulin resistant women with polycystic ovary syndrome. Fertility and Sterility 201093 1220-1226. (doi:10.1016/ j.fertnstert.2008.12.008)

38 Jones H, Sprung VS, Pugh CJ, Daousi C, Irwin A, Aziz N, Adams VL, Thomas EL, Bell JD, Kemp GJ et al. Polycystic ovary syndrome with hyperandrogenism is characterized by an increased risk of hepatic steatosis compared to nonhyperandrogenic PCOS phenotypes and healthy controls, independent of obesity and insulin resistance. Journal of Clinical Endocrinology and Metabolism 201297 3709-3716. (doi:10.1210/jc.2012-1382)

39 Tang T, Lord JM, Norman RJ, Yasmin E \& Balen AH. Insulinsensitising drugs (metformin, rosiglitazone, pioglitazone, D-chiroinositol) for women with polycystic ovary syndrome, oligo amenorrhoea and subfertility. Cochrane Database of Systematic Reviews 20125 CD003053.

40 Angelico F, Burattin M, Alessandri C, Del Ben M \& Lirussi F. Drugs improving insulin resistance for non-alcoholic fatty liver disease and/or non-alcoholic steatohepatitis. Cochrane Database of Systematic Reviews, 2007.

41 Gangale MF, Miele L, Lanzone A, Sagnella F, Martinez D, Tropea A, Moro F, Morciano A, Ciardulli A, Palla C et al. Long-term metformin treatment is able to reduce the prevalence of metabolic syndrome and its hepatic involvement in young hyperinsulinaemic overweight patients with polycystic ovarian syndrome. Clinical Endocrinology $2011 \quad \mathbf{7 5} \quad 520-527$. (doi:10.1111/j.1365-2265.2011.04093.x)

42 Brown AJ, Tendler DA, McMurray RG \& Setji TL. Polycystic ovary syndrome and severe nonalcoholic steatohepatitis: beneficial effect of modest weight loss and exercise on liver biopsy findings. Endocrine Practice 200511 319-324. (doi:10. 4158/EP.11.5.319)

43 Blouin K, Nadeau M, Perreault M, Veilleux A, Drolet R, Marceau P, Mailloux J, Luu-The $\mathrm{V} \&$ Tchernof A. Effects of androgens on adipocyte differentiation and adipose tissue explant metabolism in men and women. Clinical Endocrinology $2010 \mathbf{7 2}$ 176-188. (doi:10.1111/j.1365-2265.2009.03645.x)

44 Zhu L, Brown WC, Cai Q, Krust A, Chambon P, McGuinness OP \& Stafford JM. Estrogen treatment after ovariectomy protects against fatty liver and may improve pathway-selective insulin resistance. Diabetes 201362 424-434. (doi:10.2337/db11-1718)

45 Hewitt KN, Pratis K, Jones ME \& Simpson ER. Estrogen replacement reverses the hepatic steatosis phenotype in the male aromatase knockout mouse. Endocrinology 2004145 1842-1848. (doi:10.1210/en.2003-1369)

$46 \mathrm{Mu}$ Y, She R, Zhang H, Dong B, Huang C, Lin W, Li D \& Li X. Effects of estrogen and androgen deprivation on the progression of non-alcoholic steatohepatitis (NASH) in male Sprague-Dawley rats. Hepatology Research 200939 910-920. (doi:10.1111/j. 1872-034X.2009.00512.x)

47 Villa A, Della Torre S, Stell A, Cook J, Brown M \& Maggi A. Tetradian oscillation of estrogen receptor $\alpha$ is necessary to prevent liver lipid deposition. PNAS 2012109 11806-11811. (doi:10.1073/pnas.1205797109)

48 Tian GX, Sun Y, Pang CJ, Tan AH, Gao Y, Zhang HY, Yang XB, Li ZX \& Mo ZN. Oestradiol is a protective factor for non-alcoholic fatty liver disease in healthy men. Obesity Reviews 201213 381-387. (doi:10.1111/j.1467-789X.2011.00978.x)

49 Ogawa Y, Murata Y, Nishioka A, Inomata T \& Yoshida S. Tamoxifen-induced fatty liver in patients with breast cancer. Lancet 1998351 725. (doi:10.1016/S0140-6736(05)78493-2)

50 Gutierrez-Grobe Y, Ponciano-Rodriguez G, Ramos MH, Uribe M \& Mendez-Sanchez N. Prevalence of non alcoholic fatty liver disease in premenopausal, posmenopausal and polycystic ovary syndrome women. The role of estrogens. Annals of Hepatology $20109402-409$.
51 Florentino G, Cotrim HP, Florentino A, Padilha C, Medeiros-Neto M, Bragagnol G \& Schwingel P. Hormone replacement therapy in menopausal women: risk factor or protection to nonalcoholic fatty liver disease? Annals of Hepatology 201211 147-149.

52 Palin SL, Kumar S, Sturdee DW \& Barnett AH. HRT in women with diabetes - review of the effects on glucose and lipid metabolism. Diabetes Research and Clinical Practice $20015 \mathbf{5 4}$ 67-77. (doi:10.1016/S0168-8227(01)00277-7)

53 Sites CK, L'Hommedieu GD, Toth MJ, Brochu M, Cooper BC \& Fairhurst PA. The effect of hormone replacement therapy on body composition, body fat distribution, and insulin sensitivity in menopausal women: a randomized, double-blind, placebocontrolled trial. Journal of Clinical Endocrinology and Metabolism 200590 2701-2707. (doi:10.1210/jc.2004-1479)

54 Takahashi Y. Essential roles of growth hormone $(\mathrm{GH})$ and insulin-like growth factor-I (IGF-I) in the liver (Review). Endocrine Journal 201259 955-962. (doi:10.1507/endocrj.EJ12-0322)

55 Nishizawa H, Takahashi M, Fukuoka H, Iguchi G, Kitazawa R \& Takahashi Y. GH-independent IGF-I action is essential to prevent the development of nonalcoholic steatohepatitis in a GH-deficient rat model. Biochemical and Biophysical Research Communications 2012423 295-300. (doi:10.1016/j.bbrc.2012.05.115)

56 Xu L, Xu C, Yu C, Miao M, Zhang X, Zhu Z, Ding X \& Li Y. Association between serum growth hormone levels and nonalcoholic fatty liver disease: a cross-sectional study. PLoS ONE 20127 e44136. (doi:10.1371/journal.pone.0044136)

57 Koehler E, Swain J, Sanderson S, Krishnan A, Watt K \& Charlton M. Growth hormone, dehydroepiandrosterone and adiponectin levels in non-alcoholic steatohepatitis: an endocrine signature for advanced fibrosis in obese patients. Liver International 201232 279-286. (doi:10.1111/j.1478-3231.2011. 02637.x)

58 Ichikawa T, Nakao K, Hamasaki K, Furukawa R, Tsuruta S, Ueda Y, Taura N, Shibata H, Fujimoto M, Toriyama K et al. Role of growth hormone, insulin-like growth factor 1 and insulin-like growth factor-binding protein 3 in development of non-alcoholic fatty liver disease. Hepatology International 2007 1 287-294. (doi:10.1007/s12072-007-9007-4)

59 Arturi F, Succurro E, Procopio C, Pedace E, Mannino GC, Lugara M, Procopio T, Andreozzi F, Sciacqua A, Hribal ML et al. Nonalcoholic fatty liver disease is associated with low circulating levels of insulin-like growth factor-I. Journal of Clinical Endocrinology and Metabolism 201196 E1640-E1644. (doi:10.1210/ jc.2011-1227)

60 Fusco A, Miele L, D'Uonnolo A, Forgione A, Riccardi L, Cefalo C, Barini A, Bianchi A, Giampietro A, Cimino V et al. Nonalcoholic fatty liver disease is associated with increased GHBP and reduced GH/IGF-I levels. Clinical Endocrinology 201277 531-536. (doi:10.1111/j.1365-2265.2011.04291.x)

61 Ichikawa T, Hamasaki K, Ishikawa H, Ejima E, Eguchi K \& Nakao K. Non-alcoholic steatohepatitis and hepatic steatosis in patients with adult onset growth hormone deficiency. Gut 2003 52 914. (doi:10.1136/gut.52.6.914)

62 Takahashi Y, Iida K, Takahashi K, Yoshioka S, Fukuoka H, Takeno R, Imanaka M, Nishizawa H, Takahashi M, Seo Y et al. Growth hormone reverses nonalcoholic steatohepatitis in a patient with adult growth hormone deficiency. Gastroenterology 2007132 938-943. (doi:10.1053/j.gastro.2006.12.024)

63 Gardner CJ, Irwin AJ, Daousi C, McFarlane IA, Joseph F, Bell JD, Thomas EL, Adams VL, Kemp GJ \& Cuthbertson DJ. Hepatic steatosis, GH deficiency and the effects of GH replacement: a Liverpool magnetic resonance spectroscopy study. European Journal of Endocrinology 2012166 993-1002. (doi:10.1530/ EJE-12-0002)

64 Nikkila EA \& Pelkonen R. Serum lipids in acromegaly. Metabolism 197524 829-838. (doi:10.1016/0026-0495(75)90129-8)

65 Ciresi A, Amato MC, Pizzolanti G \& Giordano Galluzzo C. Visceral adiposity index is associated with insulin sensitivity and adipocytokine levels in newly diagnosed acromegalic patients. Journal of Clinical Endocrinology and Metabolism 201297 2907-2915. (doi:10.1210/jc.2012-1518) 
66 Madsen M, Krusenstjerna-Hafstrom T, Moller L, Christensen B, Vendelbo MH, Pedersen SB, Frystyk J, Jessen N, Hansen TK, Stodkilde-Jorgensen $\mathrm{H}$ et al. Fat content in liver and skeletal muscle changes in a reciprocal manner in patients with acromegaly during combination therapy with a somatostatin analog and a GH receptor antagonist: a randomized clinical trial. Journal of Clinical Endocrinology and Metabolism 201297 1227-1235. (doi:10.1210/jc.2011-2681)

67 Hazlehurst JM, Gathercole LL, Nasiri M, Armstrong MJ, Borrows S, Yu J, Wagenmakers AJ, Stewart PM \& Tomlinson JW. Glucocorticoids fail to cause insulin resistance in human subcutaneous adipose tissue in vivo. Journal of Clinical Endocrinology and Metabolism $2013 \quad 98$ 1631-1640. (doi:10.1210/jc.2012-3523)

68 Lemke U, Krones-Herzig A, Berriel Diaz M, Narvekar P, Ziegler A, Vegiopoulos A, Cato AC, Bohl S, Klingmuller U, Screaton RA et al. The glucocorticoid receptor controls hepatic dyslipidemia through Hes1. Cell Metabolism 20088 212-223. (doi:10.1016/ j.cmet.2008.08.001)

69 Li G, Hernandez-Ono A, Crooke RM, Graham MJ \& Ginsberg HN Effects of antisense-mediated inhibition of 11ß-hydroxysteroid dehydrogenase type 1 on hepatic lipid metabolism. Journal of Lipid Research 201152 971-981. (doi:10.1194/jlr.M013748)

70 Prasad Sakamuri SS, Sukapaka M, Prathipati VK, Nemani H, Putcha UK, Pothana S, Koppala SR, Ponday LR, Acharya V, Veetill GN et al. Carbenoxolone treatment ameliorated metabolic syndrome in WNIN/Ob obese rats, but induced severe fat loss and glucose intolerance in lean rats. PLoS ONE 20127 e50216. (doi:10.1371/journal.pone.0050216)

71 Lavery GG, Zielinska AE, Gathercole LL, Hughes B, Semjonous N, Guest P, Saqib K, Sherlock M, Reynolds G, Morgan SA et al. Lack of significant metabolic abnormalities in mice with liver-specific disruption of $11 \beta$-hydroxysteroid dehydrogenase type 1. Endocrinology 2012153 3236-3248. (doi:10.1210/en.2012-1019)

72 Livingstone D, Walker B \& Andrew R. Susceptibility to hyperinsulinaemia and fatty liver with loss of $5 \alpha$-reductase 1 occurs in rats and mice and is not androgen dependent. Endocrine Abstracts 200919136.

73 Rockall AG, Sohaib SA, Evans D, Kaltsas G, Isidori AM, Monson JP, Besser GM, Grossman AB \& Reznek RH. Hepatic steatosis in Cushing's syndrome: a radiological assessment using computed tomography. European Journal of Endocrinology 2003 149 543-548. (doi:10.1530/eje.0.1490543)

74 Zoppini G, Targher G, Venturi C, Zamboni C \& Muggeo M. Relationship of nonalcoholic hepatic steatosis to overnight lowdose dexamethasone suppression test in obese individuals. Clinical Endocrinology 200461 711-715. (doi:10.1111/j.13652265.2004.02154.x)

75 Targher G, Bertolini L, Rodella S, Zoppini G, Zenari L \& Falezza G. Associations between liver histology and cortisol secretion in subjects with nonalcoholic fatty liver disease. Clinical Endocrinology 200664 337-341. (doi:10.1111/j.1365-2265.2006. 02466.x)

76 Ahmed A, Rabbitt E, Brady T, Brown C, Guest P, Bujalska IJ, Doig C, Newsome PN, Hubscher S, Elias E et al. A switch in hepatic cortisol metabolism across the spectrum of non alcoholic fatty liver disease. PLoS ONE 20127 e29531. (doi:10.1371/ journal.pone.0029531)

77 Konopelska S, Kienitz T, Hughes B, Pirlich M, Bauditz J, Lochs H, Strasburger CJ, Stewart PM \& Quinkler M. Hepatic 11ß-HSD1 mRNA expression in fatty liver and nonalcoholic steatohepatitis. Clinical Endocrinology 200970 554-560. (doi:10.1111/j.13652265.2008.03358.x)

78 Westerbacka J, Yki-Jarvinen H, Vehkavaara S, Hakkinen AM, Andrew R, Wake DJ, Seckl JR \& Walker BR. Body fat distribution and cortisol metabolism in healthy men: enhanced $5 \beta$-reductase and lower cortisol/cortisone metabolite ratios in men with fatty liver. Journal of Clinical Endocrinology and Metabolism $2003 \mathbf{8 8}$ 4924-4931. (doi:10.1210/jc.2003-030596)

79 Rosenstock J, Banarer S, Fonseca VA, Inzucchi SE, Sun W, Yao W, Hollis G, Flores R, Levy R, Williams WV et al. The
11- $\beta$-hydroxysteroid dehydrogenase type 1 inhibitor INCB 13739 improves hyperglycemia in patients with type 2 diabetes inadequately controlled by metformin monotherapy. Diabetes Care 201033 1516-1522. (doi:10.2337/dc09-2315)

80 Feig PU, Shah S, Hermanowski-Vosatka A, Plotkin D, Springer MS, Donahue S, Thach C, Klein EJ, Lai E \& Kaufman KD. Effects of an 11ß-hydroxysteroid dehydrogenase type 1 inhibitor, MK-0916, in patients with type 2 diabetes mellitus and metabolic syndrome. Diabetes, Obesity \& Metabolism 201113 498-504. (doi:10.1111/j.1463-1326.2011.01375.x)

81 Flamant F, Baxter JD, Forrest D, Refetoff S, Samuels H, Scanlan TS, Vennstrom B \& Samarut J. International Union of Pharmacology. LIX. The pharmacology and classification of the nuclear receptor superfamily: thyroid hormone receptors. Pharmacological Reviews 200658 705-711. (doi:10.1124/pr. 58.4.3)

82 Klieverik LP, Coomans CP, Endert E, Sauerwein HP, Havekes LM, Voshol PJ, Rensen PC, Romijn JA, Kalsbeek A \& Fliers E. Thyroid hormone effects on whole-body energy homeostasis and tissue-specific fatty acid uptake in vivo. Endocrinology 2009 150 5639-5648. (doi:10.1210/en.2009-0297)

83 Nedvidkova J, Haluzik M, Bartak V, Dostalova I, Vlcek P, Racek P, Taus M, Behanova M, Svacina S, Alesci S et al. Changes of noradrenergic activity and lipolysis in the subcutaneous abdominal adipose tissue of hypo- and hyperthyroid patients: an in vivo microdialysis study. Annals of the New York Academy of Sciences 20041018 541-549. (doi:10.1196/annals.1296.067)

84 Jornayvaz FR, Lee HY, Jurczak MJ, Alves TC, Guebre-Egziabher F, Guigni BA, Zhang D, Samuel VT, Silva JE \& Shulman GI. Thyroid hormone receptor- $\alpha$ gene knockout mice are protected from dietinduced hepatic insulin resistance. Endocrinology 2012153 583-591. (doi:10.1210/en.2011-1793)

85 Sinha RA, You SH, Zhou J, Siddique MM, Bay BH, Zhu X, Privalsky ML, Cheng SY, Stevens RD, Summers SA et al. Thyroid hormone stimulates hepatic lipid catabolism via activation of autophagy. Journal of Clinical Investigation 2012 122 2428-2438. (doi:10.1172/JCI60580)

86 Riis AL, Gravholt CH, Djurhuus CB, Norrelund H, Jorgensen JO, Weeke J \& Moller N. Elevated regional lipolysis in hyperthyroidism. Journal of Clinical Endocrinology and Metabolism 200287 4747-4753. (doi:10.1210/jc.2002-020174)

87 Cachefo A, Boucher P, Vidon C, Dusserre E, Diraison F \& Beylot M. Hepatic lipogenesis and cholesterol synthesis in hyperthyroid patients. Journal of Clinical Endocrinology and Metabolism 200186 5353-5357. (doi: $10.1210 /$ jc. 86.11 .5353 )

88 Ittermann T, Haring R, Wallaschofski H, Baumeister SE, Nauck M, Dorr M, Lerch M, Meyer zu Schwabedissen HE, Rosskopf D \& Volzke H. Inverse association between serum free thyroxine levels and hepatic steatosis: results from the Study of Health in Pomerania. Thyroid 201222 568-574. (doi:10.1089/ thy.2011.0279)

89 Xu L, Ma H, Miao M \& Li Y. Impact of subclinical hypothyroidism on the development of non-alcoholic fatty liver disease: a prospective case-control study. Journal of Hepatology 201257 1153-1154. (doi:10.1016/j.jhep.2012.05.025)

90 Pagadala MR, Zein CO, Dasarathy S, Yerian LM, Lopez R \& McCullough AJ. Prevalence of hypothyroidism in nonalcoholic fatty liver disease. Digestive Diseases and Sciences $2012 \mathbf{5 7}$ 528-534. (doi:10.1007/s10620-011-2006-2)

91 Carulli L, Ballestri S, Lonardo A, Lami F, Violi E, Losi L, Bonilauri L, Verrone AM, Odoardi MR, Scaglioni F et al. Is nonalcoholic steatohepatitis associated with a high-thoughnormal thyroid stimulating hormone level and lower cholesterol levels? Internal and Emergency Medicine 20138 297-305. (doi:10.1007/s11739-011-0609-4)

92 Gardner CJ, Richardson P, Wong C, Polavarapu N, Kemp GJ \& Cuthbertson DJ. Hypothyroidism in a patient with non-alcoholic fatty liver disease. BMJ 2011342 c7199. (doi:10.1136/bmj. c7199)

93 Cable EE, Finn PD, Stebbins JW, Hou J, Ito BR, van Poelje PD, Linemeyer DL \& Erion MD. Reduction of hepatic steatosis in rats 
and mice after treatment with a liver-targeted thyroid hormone receptor agonist. Hepatology 200949 407-417. (doi:10.1002/ hep. 22572)

94 Willard FS \& Sloop KW. Physiology and emerging biochemistry of the glucagon-like peptide-1 receptor. Experimental Diabetes Research $2012 \mathbf{2 0 1 2} 470851$.

95 Ding X, Saxena NK, Lin S, Gupta NA \& Anania FA. Exendin-4, a glucagon-like protein-1 (GLP-1) receptor agonist, reverses hepatic steatosis in ob/ob mice. Hepatology 200643 173-181. (doi:10.1002/hep.21006)

96 Mells JE, Fu PP, Sharma S, Olson D, Cheng L, Handy JA, Saxena NK, Sorescu D \& Anania FA. Glp-1 analog, liraglutide, ameliorates hepatic steatosis and cardiac hypertrophy in C57BL/6J mice fed a Western diet. American Journal of Physiology. Gastrointestinal and Liver Physiology 2012302 G225-G235. (doi:10.1152/ajpgi.00274.2011)

97 Lee J, Hong SW, Chae SW, Kim DH, Choi JH, Bae JC, Park SE, Rhee EJ, Park CY, Oh KW et al. Exendin-4 improves steatohepatitis by increasing Sirt1 expression in high-fat diet-induced obese C57BL/6J mice. PLoS ONE 20127 e31394. (doi:10.1371/ journal.pone.0031394)

98 Cuthbertson DJ, Irwin A, Gardner CJ, Daousi C, Purewal T, Furlong N, Goenka N, Thomas EL, Adams VL, Pushpakom SP et al. Improved glycaemia correlates with liver fat reduction in obese, type 2 diabetes, patients given glucagon-like peptide-1 (GLP-1) receptor agonists. PLOS ONE $2012 \quad 7 \quad$ e50117. (doi:10.1371/journal.pone.0050117)

99 Armstrong MJ, Houlihan DD, Rowe IA, Clausen WH, Elbrond B, Gough SC, Tomlinson JW \& Newsome PN. Safety and efficacy of liraglutide in patients with type 2 diabetes and elevated liver enzymes: individual patient data meta-analysis of the LEAD program. Alimentary Pharmacology \& Therapeutics 201337 234-242. (doi:10.1111/apt.12149)

100 Kenny PR, Brady DE, Torres DM, Ragozzino L, Chalasani N \& Harrison SA. Exenatide in the treatment of diabetic patients with non-alcoholic steatohepatitis: a case series. American Journal of Gastroenterology $2010 \mathbf{1 0 5}$ 2707-2709. (doi:10.1038/ajg. 2010.363)

101 Ben-Jonathan N, Hugo ER, Brandebourg TD \& LaPensee CR. Focus on prolactin as a metabolic hormone. Trends in Endocrinology and Metabolism 200617 110-116. (doi:10.1016/ j.tem.2006.02.005)

102 Davis LM, Pei Z, Trush MA, Cheskin LJ, Contoreggi C, McCullough K, Watkins PA \& Moran TH. Bromocriptine reduces steatosis in obese rodent models. Journal of Hepatology $2006 \mathbf{4 5}$ 439-444. (doi:10.1016/j.jhep.2006.03.019)

103 Berinder K, Nystrom T, Hoybye C, Hall K \& Hulting AL. Insulin sensitivity and lipid profile in prolactinoma patients before and after normalization of prolactin by dopamine agonist therapy. Pituitary 201114 199-207. (doi:10.1007/s11102-010-0277-9)

104 Inancli SS, Usluogullari A, Ustu Y, Caner S, Tam AA, Ersoy R \& Cakir B. Effect of cabergoline on insulin sensitivity, inflammation, and carotid intima media thickness in patients with prolactinoma. Endocrine 2013 In press (doi:10.1007/s12020012-9857-y)

105 dos Santos Silva CM, Barbosa FR, Lima GA, Warszawski L, Fontes R, Domingues RC \& Gadelha MR. BMI and metabolic profile in patients with prolactinoma before and after treatment with dopamine agonists. Obesity $2011 \quad 19800-805$. (doi:10.1038/oby.2010.150)

106 Roth CL, Elfers CT, Figlewicz DP, Melhorn SJ, Morton GJ, Hoofnagle A, Yeh MM, Nelson JE \& Kowdley KV. Vitamin D deficiency in obese rats exacerbates nonalcoholic fatty liver disease and increases hepatic resistin and toll-like receptor activation. Hepatology 201255 1103-1111. (doi:10.1002/hep. 24737)

107 Nakano T, Cheng YF, Lai CY, Hsu LW, Chang YC, Deng JY, Huang YZ, Honda H, Chen KD, Wang CC et al. Impact of artificial sunlight therapy on the progress of non-alcoholic fatty liver disease in rats. Journal of Hepatology 201155 415-425. (doi:10.1016/j.jhep.2010.11.028)
108 Rhee EJ, Kim MK, Park SE, Park CY, Baek KH, Lee WY, Kang MI, Park SW, Kim SW \& Oh KW. High serum vitamin D levels reduce the risk for nonalcoholic fatty liver disease in healthy men independent of metabolic syndrome. Endocrine Journal 2013.

109 Targher G, Bertolini L, Scala L, Cigolini M, Zenari L, Falezza G \& Arcaro G. Associations between serum 25-hydroxyvitamin D3 concentrations and liver histology in patients with non-alcoholic fatty liver disease. Nutrition, Metabolism, and Cardiovascular Diseases 200717 517-524. (doi:10.1016/j.numecd.2006. 04.002)

110 Masuoka HC \& Chalasani N. Nonalcoholic fatty liver disease: an emerging threat to obese and diabetic individuals. Annals of the New York Academy of Sciences $2013 \mathbf{1 2 8 1} 106-122$. (doi:10.1111/nyas.12016)

111 Doycheva I, Patel N, Peterson M \& Loomba R. Prognostic implication of liver histology in patients with nonalcoholic fatty liver disease in diabetes. Journal of Diabetes and its Complications 201327 293-300. (doi:10.1016/j.jdiacomp.2012.10.008)

112 El-Serag HB, Tran T \& Everhart JE. Diabetes increases the risk of chronic liver disease and hepatocellular carcinoma. Gastroenterology 2004126 460-468. (doi:10.1053/j.gastro.2003.10.065)

113 Choi JH, Rhee EJ, Bae JC, Park SE, Park CY, Cho YK, Oh KW, Park SW \& Lee WY. Increased risk of type 2 diabetes in subjects with both elevated liver enzymes and ultrasonographically diagnosed nonalcoholic fatty liver disease: a 4-year longitudinal study. Archives of Medical Research $2013 \mathbf{4 4} 115-120$. (doi:10.1016/j.arcmed.2013.01.007)

114 Targher G, Bertolini L, Rodella S, Tessari R, Zenari L, Lippi G \& Arcaro G. Nonalcoholic fatty liver disease is independently associated with an increased incidence of cardiovascular events in type 2 diabetic patients. Diabetes Care $2007302119-2121$. (doi:10.2337/dc07-0349)

115 Targher G, Bertolini L, Rodella S, Zoppini G, Lippi G, Day C \& Muggeo M. Non-alcoholic fatty liver disease is independently associated with an increased prevalence of chronic kidney disease and proliferative/laser-treated retinopathy in type 2 diabetic patients. Diabetologia 200851 444-450. (doi:10.1007/ s00125-007-0897-4)

116 Younossi ZM, Gramlich T, Matteoni CA, Boparai N \& McCullough AJ. Nonalcoholic fatty liver disease in patients with type 2 diabetes. Clinical Gastroenterology and Hepatology 20042 262-265. (doi:10.1016/S1542-3565(04)00014-X)

117 Targher G, Pichiri I, Zoppini G, Trombetta M \& Bonora E. Increased prevalence of chronic kidney disease in patients with type 1 diabetes and non-alcoholic fatty liver. Diabetic Medicine 201229 220-226. (doi:10.1111/j.1464-5491.2011.03427.x)

118 Targher G, Pichiri I, Zoppini G, Trombetta M \& Bonora E. Increased prevalence of cardiovascular disease in type 1 diabetic patients with non-alcoholic fatty liver disease. Journal of Endocrinological Investigation 201235 535-540.

119 Targher G, Bertolini L, Padovani R, Rodella S, Zoppini G, Pichiri I, Sorgato C, Zenari L \& Bonora E. Prevalence of non-alcoholic fatty liver disease and its association with cardiovascular disease in patients with type 1 diabetes. Journal of Hepatology $2010 \mathbf{5 3}$ 713-718. (doi:10.1016/j.jhep.2010.04.030)

120 Chalasani N, Younossi Z, Lavine JE, Diehl AM, Brunt EM, Cusi K, Charlton M \& Sanyal AJ. The diagnosis and management of nonalcoholic fatty liver disease: practice guideline by the American Gastroenterological Association, American Association for the Study of Liver Diseases, and American College of Gastroenterology. Gastroenterology $2012 \mathbf{1 4 2 ~ 1 5 9 2 - 1 6 0 9 . ~ ( d o i : 1 0 . 1 0 5 3 / ~}$ j.gastro.2012.04.001)

121 Saltiel AR \& Kahn CR. Insulin signalling and the regulation of glucose and lipid metabolism. Nature $2001 \mathbf{4 1 4} 799-806$. (doi:10.1038/414799a)

122 Miquilena-Colina ME, Lima-Cabello E, Sanchez-Campos S, Garcia-Mediavilla MV, Fernandez-Bermejo M, LozanoRodriguez T, Vargas-Castrillon J, Buque X, Ochoa B, Aspichueta P et al. Hepatic fatty acid translocase CD36 upregulation is associated 
with insulin resistance, hyperinsulinaemia and increased steatosis in non-alcoholic steatohepatitis and chronic hepatitis C. Gut 2011 60 1394-1402. (doi:10.1136/gut.2010.222844)

123 Groop LC, Saloranta C, Shank M, Bonadonna RC, Ferrannini E \& DeFronzo RA. The role of free fatty acid metabolism in the pathogenesis of insulin resistance in obesity and noninsulindependent diabetes mellitus. Journal of Clinical Endocrinology and Metabolism 199172 96-107. (doi:10.1210/jcem-72-1-96)

124 Flannery C, Dufour S, Rabol R, Shulman GI \& Petersen KF. Skeletal muscle insulin resistance promotes increased hepatic de novo lipogenesis, hyperlipidemia, and hepatic steatosis in the elderly. Diabetes 201261 2711-2717. (doi:10.2337/ db12-0206)

125 Kawano Y \& Cohen DE. Mechanisms of hepatic triglyceride accumulation in non-alcoholic fatty liver disease. Journal of Gastroenterology $2013 \mathbf{4 8}$ 434-441. (doi:10.1007/s00535013-0758-5)
126 Sanyal AJ, Campbell-Sargent C, Mirshahi F, Rizzo WB, Contos MJ, Sterling RK, Luketic VA, Shiffman ML \& Clore JN. Nonalcoholic steatohepatitis: association of insulin resistance and mitochondrial abnormalities. Gastroenterology 2001120 1183-1192. (doi:10.1053/ gast.2001.23256)

127 Regnell SE \& Lernmark A. Hepatic steatosis in type 1 diabetes. Review of Diabetic Studies 20118 454-467. (doi:10.1900/RDS. 2011.8.454)

128 Cleland SJ, Fisher BM, Colhoun HM, Sattar N \& Petrie JR. Insulin resistance in type 1 diabetes: what is 'double diabetes' and what are the risks? Diabetologia 201356 1462-1470. (doi:10.1007/ s00125-013-2904-2)

Received 8 April 2013

Revised version received 2 May 2013

Accepted 7 May 2013 